\title{
The potential effects of saponins on ruminal fermentation
}

H R Lima Neto, A S Chaudhry, M M H Khan, G S Rocha

Newcastle University, Newcastle, United Kingdom

Email:helio.limaneto@gmail.com

Introduction Mitigating greenhouse gas emissions from ruminants by feeding natural compounds has been a target for many researchers. The effect of saponins is dependant on the plant from which they are extracted and the diet fed to the animals. So, due to these constraints to the exploitation of saponins in ruminant production, a short insight of its use as a methane inhibitor will be drawn in this paper.

Materials and methods A literature search was performed and 59 studies were then used in a meta-analysis simple regression. The model used included the overall size effect, the effect of the size of each study, and the variation between studies. A summary was compiled and the main results of the effect of saponins for ruminants as well as sources providing beneficial results are presented (Figures $1 \& 2$ ).

Discussion The biological effects of saponins on microorganisms are related to the increase in microbial membrane porosity. Interaction with the outer environment tends to arise and then the effects of saponins vary considerably given that contents of rumen liquor differ widely from animal to animal. The trend observed when the compilation of 59 studies was analysed demonstrated that 16 of them significantly reduced methane production (MP) (Figure 1) (Hart et al, 2008) $(\mathrm{p}<0,05)$. However we interpret these data as showing only very few examples of saponins impacting on rumen fermentation. This approach to trials included in this study can validate saponins as a potential methane inhibitor to be used in modern animal nutrition. Several authors as mentioned by $\mathrm{Hu}$ et al. (2005) have understood that the way saponins are assessed is important and can completely change the outcomes of a trial (Figure 2) ( $>0.05$ ).

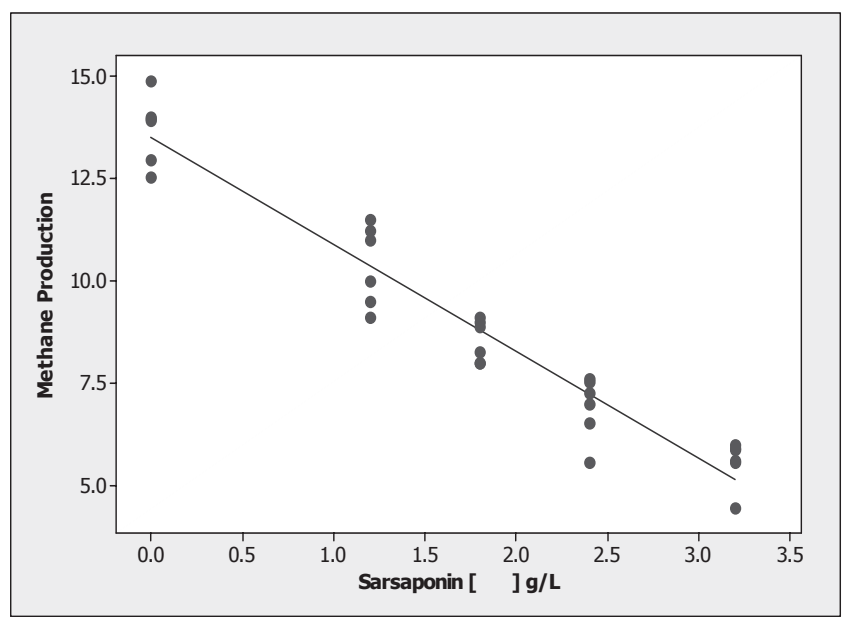

Figure 1 Meta-analysis of the effect of sarsaponin (S) as a methane inhibitor $(\mathrm{MP}=14.10-2.609 * \mathrm{~S} g / \mathrm{L})(\mathrm{p}<0.05)$

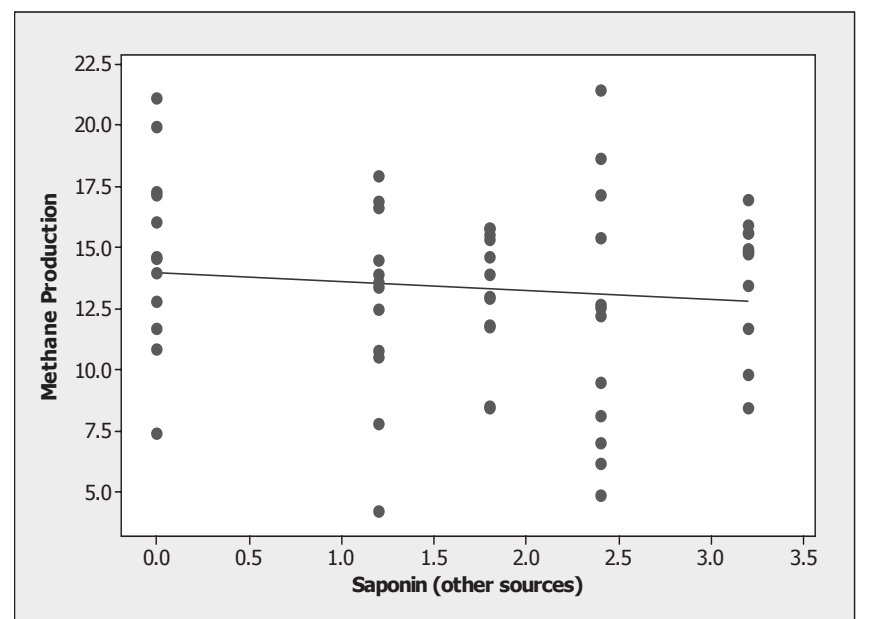

Figure 2 Meta-analysis of the effect of sources of saponin (OS) other than sarsaponin as methane inhibitors $(\mathrm{MP}=13.98-0.2637 * \mathrm{OS} \mathrm{g} / \mathrm{L})(\mathrm{p}>0.05)$

Results The results shown above seem to have sources ( $S$. saponaria fruit) and specific characteristics of saponins (chemical Sarsaponin) as the principal effect for methane suppression (Hess et al., 2004). Over 50 studies in the literature evaluating the effects of saponins on rumen fermentation, including methane modification, found no evidence that these secondary metabolites could reduce the amount of this greenhouse gas. Indeed, none have used $S$. saponaria where Sarsaponin is the source of saponins. There is a need for new trials using distinct sources of saponins.

Conclusions Saponins can manipulate ruminal fermentation but the change in methane production is questionable and demands further investigation. These should focus on specific classes of saponins. Methanogenic archea seems to be little affected by these chemical compounds but the real dose-response and mechanisms are still unclear.

Acknowledgements Mr. Helio Lima is grateful to Brazilian Government by providing his CAPES PhD Scholarship

\section{References}

Hart, K.J., Yáñez-Ruiz, D.R., Duval, S.M., McEwan, N.R., Newbold, C.J., 2008. Plant extracts to manipulate rumen fermentation. Animal Feed Science and Technology 147, 8-35.

Hess, H.D., Beuret, R.A., Lotscher, M., Hindrichsen, I.K., Machmuller, A., Carulla, J.E., Lascano,C.E. and Kreuzer, M., Ruminal fermentation, methanogenesis and nitrogen utilization of sheep receiving tropical grass hay-concentrate diets offered with Sapindus saponaria fruits and Cratylia argentea foliage, Animal Science 79 (2004), pp. 177-189.

Hu, W.-L., Liu, J.-X., Ye, J.-A., Wu, Y.-M., Guo, Y.-Q., 2005. Effect of tea saponin on rumen fermentation in vitro. Animal Feed Science and Technology 120, 333-339. 